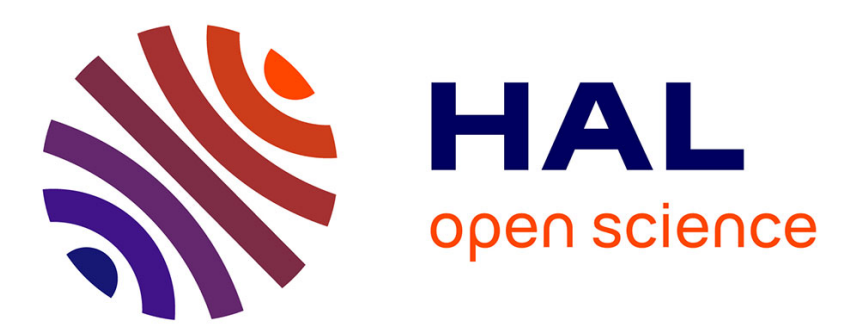

\title{
Logical definition of analogical proportion and its fuzzy extensions
}

\author{
Laurent Miclet, Henri Prade
}

\section{To cite this version:}

Laurent Miclet, Henri Prade. Logical definition of analogical proportion and its fuzzy extensions. Annual Meeting of the North American Fuzzy Information Processing Society (NAFIPS 2008), May 2008, New-York, United States. 10.1109/NAFIPS.2008.4531257 . hal-03358849

\section{HAL Id: hal-03358849 https://hal.science/hal-03358849}

Submitted on 30 Sep 2021

HAL is a multi-disciplinary open access archive for the deposit and dissemination of scientific research documents, whether they are published or not. The documents may come from teaching and research institutions in France or abroad, or from public or private research centers.
L'archive ouverte pluridisciplinaire HAL, est destinée au dépôt et à la diffusion de documents scientifiques de niveau recherche, publiés ou non, émanant des établissements d'enseignement et de recherche français ou étrangers, des laboratoires publics ou privés. 


\section{Logical definition of analogical proportion and its fuzzy extensions}

\author{
Laurent Miclet \\ IRISA / ENSSAT \\ Université de Rennes 1 \\ 6 rue de Kérampont, 22305 Lannion, France \\ miclet@enssat.fr
}

\author{
Henri Prade \\ Institut de Recherche en Informatique de Toulouse (IRIT) \\ Université Paul Sabatier \\ 118 route de Narbonne, 31062 Toulouse Cedex 9, France \\ prade@irit.fr
}

\begin{abstract}
An analogical proportion is a statement of the form "A is to B as C is to D". In a logical setting, items A, B, C and $D$ are Boolean vectors. This notion is at the core of analogical reasoning. This paper proposes a sound definition of analogical proportion, based on a logical expression that holds true for each vector component if and only if the analogical proportion holds true. The analogical equation, where $D$ is unknown, is also discussed. The logical expression of the analogical proportion has several equivalent forms, which may lead to distinct extensions when the vector components takes its values in the unit interval, depending on the choice of the multiple-valued connectives. Applications to case-based and approximate reasoning, and to learning are outlined.
\end{abstract}

\section{INTRODUCTION}

Reasoning by analogy, according to the analogical proportion pattern " $\mathrm{A}$ is to $\mathrm{B}$ as $\mathrm{C}$ is to $\mathrm{D}$ ", consists firstly in observing two particular situations $\mathrm{A}$ and $\mathrm{B}$ and to evaluate in which way A can be transformed into B, taking into account their similarity. Then, observing a third situation $\mathrm{C}$, it amounts to transform C into D in the same way. Hence, this way of reasoning uses three situations to build a fourth one. Analogical reasoning, which has been identified by philosophers in the Antiquity as early as deductive reasoning, is usually regarded as a form of reasoning that is beyond logic, since it leads to conclusions whose truth is not guaranteed, which contrasts with the case of deductive reasoning. It seems that for this reason the formalization of analogical reasoning is remained much less developed than for deduction, and does not use in general any logical setting.

Although artificial intelligence has started early to handle analogical reasoning and to apply it (e.g. [11], [16], [26]), it is only in the last twenty years that an operational form of analogical reasoning, called Case-Based Reasoning [1], has been considerably developed and applied. It uses a repertory of known cases stored as pairs (problem, solution). When a new problem $\mathrm{C}$ is encountered for which no solution is known, problems A similar to $\mathrm{C}$ are retrieved, where $\mathrm{A}$ appears in a stored pair $(\mathrm{A}, \mathrm{B})=$ (problem, solution), and then using some adaptation technique the solution $\mathrm{B}$ of problem A is transposed into a (potential) solution $\mathrm{D}$ for problem $\mathrm{C}$, taking into account in what respects $\mathrm{A}$ and $\mathrm{C}$ are similar and how they differ. In analogical terms, D should be to $\mathrm{C}$ as $\mathrm{B}$ is to A.

Fuzzy logic tools have also been proposed for describing such situations by means of fuzzy rules of the form "the more similar A and B, the more (plausibly) similar C and D" using fuzzy similarity relations, and for aggregating potential solutions when several relevant cases are retrieved with respect to a current problem [8], [10], [13]. Thus, analogical reasoning appears to be close to approximate reasoning up to the important difference that analogy handles particular situations, while fuzzy if-then rules have a generic flavor and approximate reasoning remains deductive in essence [12], [22], [17].

The present paper starts from a logical definition suggested by Klein [14] in 1982, which is discussed with respect to formal properties that are desirable for the analogical proportion, and which have been advocated in recent works [18], [19], [26]. This logical definition is shown to be too general since it also encompasses some cases that do not correspond to a genuine analogy. Then, a new logical definition that exactly covers the analogical proportion is proposed. This definition can be put under different, noticeable, equivalent forms. This provides a starting point for discussing graded extensions of these different forms using various families of multiple-valued connectives. The modeling of the analogical dissimilarity [19], [20], which corresponds to " $\mathrm{D}$ is not to $\mathrm{C}$ what $\mathrm{B}$ is to $\mathrm{A}$ ", is also discussed in the binary and in the multiple-valued case. Applications to casebased reasoning, approximate reasoning, and learning are outlined.

\section{BINARY CASE}

An analogical proportion is a statement of the form "A is to $\mathrm{B}$ as $\mathrm{C}$ is to $\mathrm{D}$ ". This will be denoted by (A : B :: C : D). We shall assume that the items A, B, C, and D can be represented by vectors having $n$ components, i.e., $\mathrm{A}=\left(\mathrm{a}_{1}, \ldots\right.$, $\left.a_{n}\right), \ldots, D=\left(d_{1}, \ldots, d_{n}\right)$. In the binary case, each component is equal to 0 or 1 . In section III, we shall study the case where each vector component takes its value in the unit interval $[0$, 1]. As further discussed in section IV, the components of vectors such as $\left(a_{1}, \ldots, a_{n}\right)$, may receive two interpretations in practice. They may be represent

- either as the membership degrees of the elements of a finite domain $\mathrm{X}=\left(\mathrm{x}_{1}, \ldots, \mathrm{x}_{\mathrm{n}}\right)$ with respect to $\mathrm{A}, \mathrm{B}, \mathrm{C}$ and $\mathrm{D}$ respectively, viewed as subsets of $\mathrm{X}$;

- or as a n-tuple of truth degrees with respect to $n$ properties (possibly graded in III) used for describing items A, B, C, D. The first and the second interpretations will be respectively termed "set element-interpretation", and "object propertiesinterpretation". If (A : B :: C : D) holds, it means that $\left(\mathrm{a}_{\mathrm{i}}: \mathrm{b}_{\mathrm{i}}\right.$ $\because: \mathrm{c}_{\mathrm{i}}: \mathrm{d}_{\mathrm{i}}$ ) holds for all the components $i$ of the descriptions of $\mathrm{A}, \mathrm{B}, \mathrm{C}$ and $\mathrm{D}$, with $i=1$, n. If there is no need to specify one particular component, we shall simply write $(a: b:: c: d)$. 
One might think of introducing approximate or partial analogies by only requiring that $\left(\mathrm{a}_{\mathrm{i}}: \mathrm{b}_{\mathrm{i}}:: \mathrm{c}_{\mathrm{i}}: \mathrm{d}_{\mathrm{i}}\right)$ holds for most vector components $i$, but this will not be not studied here.

In the following, we work at the semantic level, and we use standard notations for denoting connective functions: $\neg($ negation $), \wedge($ conjunction $), \quad v($ disjunction $), \rightarrow$ (implication), $\equiv$ (equivalence), $\Delta$ (exclusive or). For any twoplace connective $*, \mathrm{a} * \mathrm{~b} \in\{0,1\}$ in the binary case, and $\mathrm{a} *$ $\mathrm{b} \in[0,1]$ in the graded case. $\neg \mathrm{a} \in\{0,1\}$ or $\neg \mathrm{a} \in[0,1]$ as well. In the following, we look for logical expressions of the analogical proportion $(a: b:: c: d)$.

\section{A. Background}

About twenty-five years ago, Klein [14], a specialist in anthropology, presented in an artificial intelligence conference, in terms of binary truth-like tables, what he considered as being the basic pattern of the analogical reasoning, using many illustrative examples. The paper [14] has a rather unusual title for a computer science conference, and was not suggesting any particular relation with analogy, as it can be seen. It may be the reason why the approach had no real posterity in artificial intelligence until now, although it has in anthropology [23], [15]. Still Klein proposed a mathematical operator that he called ATO (for 'Appositional Transformation Operator'), whose repeated use enables him to compute analogical proportions. This operator is in fact the logical equivalence connective $\mathrm{a} \equiv \mathrm{b}=1$ if $\mathrm{a}=\mathrm{b}$, and $\mathrm{a} \equiv \mathrm{b}=0$ otherwise. What is proposed in [14] amounts to write

$$
(a: b:: c: d)=(a \equiv b) \equiv(c \equiv d)
$$

even it is never explicitly stated as such. Let us illustrate the idea on an example from [14]. Each of the four statements A, $\mathrm{B}, \mathrm{C}$ and $\mathrm{D}$ are represented by a 4 -tuple encoding 4 binary properties: Sex, Adult, Attitude, Light. Thus, A = "Boys love light" is encoded by ( $\left(\begin{array}{llll}1 & 0 & 1 & 1\end{array}\right)$ (Klein used a slightly more complicated, but equivalent encoding). From the following three statements:

$\begin{array}{lrlcc} & \text { Sex Adult } & \text { Attitude } & \text { Light } \\ \text { A: Boys love light } & 1 & 0 & 1 & 1 \\ \text { B: Women hate light } & 0 & 1 & 0 & 1 \\ \text { C: Girls hate dark } & 0 & 0 & 0 & 0\end{array}$

it is inferred that $\mathrm{D}=\left(\begin{array}{llll}1 & 1 & 1 & 0\end{array}\right)$, i. e., "Men love dark". Indeed, it can be checked that

$$
\begin{aligned}
& \mathrm{A} \equiv \mathrm{B}=\left(\mathrm{a}_{1} \equiv \mathrm{b}_{1}, \mathrm{a}_{2} \equiv \mathrm{b}_{2}, \mathrm{a}_{3} \equiv \mathrm{b}_{3}, \mathrm{a}_{4} \equiv \mathrm{b}_{4}\right)=\left(\begin{array}{llll}
0 & 0 & 0 & 1
\end{array}\right) \\
& \text { and that } \\
& \qquad \mathrm{C} \equiv \mathrm{D}=\left(\mathrm{c}_{1} \equiv \mathrm{d}_{1}, \mathrm{c}_{2} \equiv \mathrm{d}_{2}, \mathrm{c}_{3} \equiv \mathrm{d}_{3}, \mathrm{c}_{4} \equiv \mathrm{d}_{4}\right)=\left(\begin{array}{llll}
0 & 0 & 0 & 1
\end{array}\right) \\
& \text { and thus } \quad(\mathrm{A} \equiv \mathrm{B}) \equiv\left(\begin{array}{lll}
\mathrm{C} \equiv \mathrm{D})=\left(\begin{array}{llll}
1 & 1 & 1 & 1
\end{array}\right) .
\end{array}\right.
\end{aligned}
$$
and that

As it can be checked, there is always a unique solution $\mathrm{X}$ such as $(\mathrm{C} \equiv \mathrm{X}) \equiv(\mathrm{A} \equiv \mathrm{B})$. Moreover, Klein [14] suggested that for each vector component, the solution $\mathrm{x}$ of $(\mathrm{a}: \mathrm{b}:: \mathrm{c}: \mathrm{x})=$ $(\mathrm{a} \equiv \mathrm{b}) \equiv(\mathrm{c} \equiv \mathrm{x})=1$ is given by

$$
\mathrm{x}=\mathrm{c} \equiv(\mathrm{a} \equiv \mathrm{b}) \text {. }
$$

Although definition (1) looks appealing, it nevertheless has a flaw. Some of its properties are undesirable w.r.t. the basic properties of analogical proportion. Actually, as we shall see, it covers cases that we are reluctant to view as genuine analogical proportions.

The characteristic properties of the analogical proportion have been identified by different authors (see in particular [18], [19], [26]). They are:

$$
\begin{array}{ll}
\text { (S) } & (\mathrm{a}: \mathrm{b}:: \mathrm{c}: \mathrm{d})=(\mathrm{c}: \mathrm{d}:: \mathrm{a}: \mathrm{b}) \\
\text { (CP) } & (\mathrm{a}: \mathrm{b}:: \mathrm{c}: \mathrm{d})=(\mathrm{a}: \mathrm{c}:: \mathrm{b}: \mathrm{d}) \\
\text { (ID1) } & (\mathrm{a}: \mathrm{a}: \mathrm{b}: \mathrm{x}) \Rightarrow \mathrm{x}=\mathrm{b}
\end{array}
$$

where (S) expresses a symmetry in the comparison, namely if "A is to B as C is to D" then we should also have "C is to D what $\mathrm{A}$ is to $\mathrm{B}$ ", while $(\mathrm{CP})$ allows for a central permutation, i.e., it should be also allowed to say that "A is to C as B is to D". (ID) expresses an "identity" determinism. The above properties are obviously satisfied by numerical models where an analogical proportion is viewed as an equality of ratios $(\mathrm{a} / \mathrm{b}$ $=\mathrm{c} / \mathrm{d})$, or of differences $(\mathrm{a}-\mathrm{b}=\mathrm{c}-\mathrm{d})$, with $\mathrm{a}, \mathrm{b}, \mathrm{c}, \mathrm{d}$ being real numbers. These properties become natural requirements for a logical representation as well.

These properties have several immediate consequences:
(I) $\quad(\mathrm{a}: \mathrm{b}:: \mathrm{c}: \mathrm{d})=(\mathrm{b}: \mathrm{a}:: \mathrm{d}: \mathrm{c})$
(EP) $\quad(a: b:: c: d)=(d: b:: c: a)$
(SR1) $\quad(a: b:: c: d)=(d: c:: b: a)$
(SR2) $\quad(a: b:: c: d)=(b: d:: a: c)$
(SR3) $\quad(a: b:: c: d)=(c: a:: d: b)$
(ID2) $\quad(a: b:: a: x) \Rightarrow x=b$

where (I) allows for the inversion of the relations (obtained by applying (CP), (S) and (CP)), (EP) allows for external permutation (obtained by applying (I), (S) and (CP)), (SR1), (SR2) and (SR3) expressing symmetries for the reading (and can be respectively obtained by (I) and (S), (CP) and (S), and (S) and (CP)). (ID2) is obtained from (ID1) and (CP).

It is obvious that definition (1) satisfies (S), i. e. $(\mathrm{a} \equiv \mathrm{b}) \equiv(\mathrm{c} \equiv \mathrm{d})=(\mathrm{c} \equiv \mathrm{d}) \equiv(\mathrm{a} \equiv \mathrm{b})$

and it can be checked on truth tables that (CP) holds, namely $(a \equiv b) \equiv(c \equiv d)=(a \equiv c) \equiv(b \equiv d)$.

However, it has some undesirable properties such as $(a \equiv b) \equiv(c \equiv d)=(b \equiv a) \equiv(c \equiv d)$

Indeed if "A is to B what C is to D", it does not generally entail that "B is to A as $C$ is to $D$ ". Let us examine the cases where $(a \equiv b) \equiv(c \equiv d)=1$. They are listed in Table 1 .

\begin{tabular}{|c|c|c|c|c|c|}
\hline & $\mathrm{a}$ & $\mathrm{b}$ & $\mathrm{c}$ & $\mathrm{d}$ & $(\mathrm{a} \equiv \mathrm{b}) \equiv(\mathrm{c} \equiv \mathrm{d})$ \\
\hline 1 & 1 & 1 & 1 & 1 & 1 \\
\hline 2 & 1 & 1 & 0 & 0 & 1 \\
\hline 3 & 1 & 0 & 1 & 0 & 1 \\
\hline 4 & 1 & 0 & 0 & 1 & 1 \\
\hline 5 & 0 & 1 & 1 & 0 & 1 \\
\hline 6 & 0 & 1 & 0 & 1 & 1 \\
\hline 7 & 0 & 0 & 1 & 1 & 1 \\
\hline 8 & 0 & 0 & 0 & 0 & 1 \\
\hline
\end{tabular}

Table 1 
For the eight other possible combinations of values of a, $\mathrm{b}, \mathrm{c}$, and $\mathrm{d}$ that do not appear in Table $1,(\mathrm{a} \equiv \mathrm{b}) \equiv(\mathrm{c} \equiv \mathrm{d})=$ 0 . Cases 1, 2, 7, and 8 corresponds to situations where a and $\mathrm{b}$ on the one hand and $\mathrm{c}$ and $\mathrm{d}$ on the other hand are identical. Cases 3 and 6 correspond to changes from a to $b$, and from $c$ to d, that go in the same sense. All these cases clearly fit the semantics of the analogical proportion. The two other cases, namely 4 and 5, do not fit the idea that a is to $\mathrm{b}$ as $\mathrm{c}$ is to $\mathrm{d}$, since the changes from $a$ to $b$ and from $c$ to $d$ are not in the same sense.

Remark 1. The expression (1) can be rewritten in other logically equivalent, remarkable forms that emphasize other views of analogy. Let us mention two of them. Thus we have

$$
\begin{aligned}
(a: b:: c: d)=(a \equiv b) \equiv(c \equiv d)=(a \Delta b) \equiv(c \Delta d) \\
=((a \rightarrow b) \equiv(c \rightarrow d)) \wedge((a \rightarrow c) \equiv(b \rightarrow d))
\end{aligned}
$$

The expression (3) emphasizes the similarity of the ways the items differ, since the symmetrical difference $\Delta$ is used, while (4) points out the "parallels" that should exist in the structure.

\section{B. Equivalent forms of the right definition}

As suggested by the results of the previous subsection, we are looking for a logical expression that only cover cases 1 , $2,3,6,7,8$ in Table 1, in order to be faithful to the idea of analogical proportion.

One way to obtain such a formula is to start from (1) and then to add further constraints in order to exclude cases (4) and (5). The formula $\mathrm{F}=(\mathrm{a} \Delta \mathrm{b}) \wedge(\mathrm{a} \Delta \mathrm{c}) \wedge(\mathrm{b} \Delta \mathrm{d})$ takes value 1 only for $(a, b, c, d)=(0,1,1,0)$ or for $(a, b, c, d)=(1,0,0$, $1)$, i.e. the two cases we want to exclude. This leads to the expression

$$
\begin{aligned}
(\mathrm{a}: \mathrm{b}:: \mathrm{c}: \mathrm{d}) & =((\mathrm{a} \equiv \mathrm{b}) \equiv(\mathrm{c} \equiv \mathrm{d})) \Delta \mathrm{F} \\
=((\mathrm{a} \equiv \mathrm{b}) & \equiv(\mathrm{c} \equiv \mathrm{d})) \Delta((\mathrm{a} \Delta \mathrm{b}) \wedge(\mathrm{a} \Delta \mathrm{c}) \wedge(\mathrm{b} \Delta \mathrm{d}))
\end{aligned}
$$

There also exist formulas that are equivalent to (5), but which better reflect the analogical process, such as

$$
(\mathrm{a}: \mathrm{b}:: \mathrm{c}: \mathrm{d})=((\mathrm{a} \equiv \mathrm{b}) \equiv(\mathrm{c} \equiv \mathrm{d})) \wedge((\mathrm{a} \Delta \mathrm{b}) \rightarrow(\mathrm{a} \equiv \mathrm{c}))(6)
$$

Indeed (6) expresses in its second component that a and c should be identical where $a$ and $b$ differs, which is a natural constraint for making sure that the change from $\mathrm{c}$ to $\mathrm{d}$ will be in the same sense as the one from a to b). (6) can be equivalently rewritten

$$
(a: b:: c: d)=((a \equiv b) \equiv(c \equiv d)) \wedge((a \equiv b) \vee(a \equiv c))
$$

since $\mathrm{a} \equiv \mathrm{b}=\neg(\mathrm{a} \Delta \mathrm{b})$ and $\mathrm{a} \rightarrow \mathrm{b}=\neg \mathrm{a} \vee \mathrm{b}$. There also exist expressions equivalent to (5) or to (6) that are symmetrical. Two noticeable ones are:

$$
\begin{gathered}
(a: b:: c: d)=((a \equiv b) \wedge(c \equiv d)) \vee((a \equiv c) \wedge(b \equiv d))(8) \\
(a: b:: c: d)=((a \rightarrow b) \equiv(c \rightarrow d)) \wedge((b \rightarrow a) \equiv(d \rightarrow c))(9)
\end{gathered}
$$

These two expressions well reflect the structure of analogical proportion. Note that the second expression parallels at the logical level the difference-based view

$$
(a-b)=(c-d)
$$

of the analogical proportion $(\mathrm{a}: \mathrm{b}:: \mathrm{c}: \mathrm{d})$. Indeed, when $\mathrm{a}$ and $\mathrm{b}$ are equal to 0 or $1, \mathrm{a}-\mathrm{b} \in\{-1,0,1\}$, and thus $(\mathrm{a}-\mathrm{b})$ is not a logical connective, but keeps track of the sense of the change if any. It is why since (9) works in $\{0,1\}$, the equivalences in (9) are stated in the both senses (remember that $\mathrm{a} \rightarrow \mathrm{b}=1$ if $\mathrm{a} \leq \mathrm{b}$ and $\mathrm{a} \rightarrow \mathrm{b}=0$ if $\mathrm{a}>\mathrm{b}$, and observe that the condition $\mathrm{a} \leq \mathrm{b}$ covers two situations: $\mathrm{a}=\mathrm{b}$ (no change) or $\mathrm{a}<\mathrm{b}$ (change)).

We can now state the following results:

Proposition 1: The definitions (5), (6), (7), (8) and (9) of the analogical proportion $(\mathrm{a}: \mathrm{b}:: \mathrm{c}: \mathrm{d})$ are equivalent, and take the value 1 for and only for the 6 situations of Table 1 that differs from $\left(\begin{array}{lll}a & b & c\end{array}\right)=\left(\begin{array}{llll}1 & 0 & 0 & 1\end{array}\right)$ and from $(a b c d)=\left(\begin{array}{llll}0 & 1 & 1 & 0\end{array}\right)$.

Proposition 2: If $\mathrm{a} \rightarrow \mathrm{b}=1$ and $(\mathrm{a}: \mathrm{b}:: \mathrm{c}: \mathrm{d})=1$ then $\mathrm{c} \rightarrow \mathrm{d}$ $=1$, where $(\mathrm{a}: \mathrm{b}:: \mathrm{c}: \mathrm{d})$ is defined by $(5),(6),(7),(8)$ or $(9)$.

Proposition 3: $(\mathrm{a}: \mathrm{b}:: \mathrm{c}: \mathrm{d})=1$ and $(\mathrm{c}: \mathrm{d}:: \mathrm{e}: \mathrm{f})=1$ entails $(\mathrm{a}: \mathrm{b}:: \mathrm{e}: \mathrm{f})=1$, where $(\mathrm{a}: \mathrm{b}:: \mathrm{c}: \mathrm{d})$ is defined by (5), (6), $(7),(8)$ or $(9)$.

Proposition 4: A triple (a b c) can be completed by $\mathrm{d}$ in such a way that $(a: b:: c: d)=1$ if and only if

$$
(\mathrm{a} \equiv \mathrm{b}) \vee(\mathrm{a} \equiv \mathrm{c})=1
$$

Proposition 5: When it exists, the unique solution of the equation $(\mathrm{a}: \mathrm{b}:: \mathrm{c}: \mathrm{x})=1$ is logically expressed by

$$
\mathrm{x}=(\mathrm{a} \equiv(\mathrm{b} \equiv \mathrm{c}))
$$

Let us comment these results. Proposition 1 ensures that we have found the appropriate logical expression(s) for the analogical proportion. Proposition 2 ensures that if "A is to B as $\mathrm{C}$ is to $\mathrm{D}$ ", and $\mathrm{B}$ is more general than A, D should be more general than C. Proposition 3 expresses that transitivity holds for analogical proportion, as expected. Proposition 4 points out that a should be equivalent to $\mathrm{b}$ or to $\mathrm{c}$, in order to get rid of the two triples $\left(\begin{array}{ll}a & b\end{array}\right)=\left(\begin{array}{lll}1 & 0 & 0\end{array}\right)$ and $\left(\begin{array}{ll}a \\ b\end{array}\right)=\left(\begin{array}{lll}0 & 1 & 1\end{array}\right)$ that cannot be completed analogically (see Table 1). Note that the required condition is explicitly part of definition (7). It is also interesting to write the counterpart of this condition in the "set element-interpretation" (introduced at the beginning of section II). Then $a, b, c$, and $d$ stand for the current membership degree of an element of a referential X to A, B, $\mathrm{C}$, and $\mathrm{D}$ respectively. Then the impossibility of $(\mathrm{a} b \mathrm{c})=\left(\begin{array}{ll}1 & 0\end{array}\right.$ $0)$ and $\left(\begin{array}{ll}a & b \\ c\end{array}\right)=\left(\begin{array}{lll}0 & 1 & 1\end{array}\right)$ translates respectively into $A \cap\left(B^{C} \cap\right.$ $\left.\mathrm{C}^{\mathrm{C}}\right)=\varnothing$ and $\mathrm{A}^{\mathrm{C}} \cap(\mathrm{B} \cap \mathrm{C})=\varnothing$, i.e., the logical condition for analogical completion $(a \equiv b) \vee(a \equiv c)=1$ can be written in set terms as

$$
\mathrm{B} \cap \mathrm{C} \subseteq \mathrm{A} \subseteq \mathrm{B} \cup \mathrm{C}
$$


This condition has been pointed out in recent works [18], [19], [20] in a set-oriented approach to the study of analogical proportion.

Proposition 5 provides a compact writing of the solution of an analogical proportion. This is the solution already suggested in [14] by Klein. There exist other expressions of the solution under the requirement of Proposition 4. Namely,

Proposition 6: When it exists, the unique solution of the equation $(\mathrm{a}: \mathrm{b}:: \mathrm{c}: \mathrm{x})=1$ is also logically expressed by

$$
\begin{aligned}
\mathrm{x} & =((\mathrm{b} \vee \mathrm{c}) \wedge \neg \mathrm{a}) \vee(\mathrm{b} \wedge \mathrm{c}) \\
& =(\mathrm{b} \wedge \neg \mathrm{a}) \vee(\mathrm{c} \wedge \neg \mathrm{a}) \vee(\mathrm{a} \wedge \mathrm{b} \wedge \mathrm{c})
\end{aligned}
$$

Proposition 6, which can be easily checked on a truth table, is nothing but the logical counterpart of expressions recently proposed in [18], [19], [20], in the "set elementinterpretation". Both Proposition 5 and Proposition 6 could be applied when $(\mathrm{a} b \mathrm{c})$ cannot be analogically completed, i.e. when $(\mathrm{a} \equiv \mathrm{b}) \vee(\mathrm{a} \equiv \mathrm{c})=0$. Mind that while Proposition 5 applied to the two "undesirable cases" $\left(\mathrm{a}\right.$ b c) $=\left(\begin{array}{lll}1 & 0 & 0\end{array}\right)$ and $(\mathrm{a}$ $\mathrm{b} \mathrm{c})=\left(\begin{array}{lll}0 & 1 & 1\end{array}\right)$ yield $\mathrm{x}=1$ and $\mathrm{x}=0$ respectively, Proposition 6 gives the converse, namely $x=0$ and $x=1$ respectively in the two cases. This means that the expression $\mathrm{x}=(\mathrm{a} \equiv(\mathrm{b} \equiv \mathrm{c}))$ of Proposition 5 is logically equivalent to the two expressions in Proposition 6, only under condition $(a \equiv b) \vee(a \equiv c)=1$.

Besides, the completion obtained by Proposition 5 for

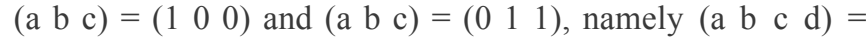
$\left(\begin{array}{llll}1 & 0 & 0 & 1\end{array}\right)$ and $\left(\begin{array}{lll}a \\ b & c & d\end{array}\right)=\left(\begin{array}{llll}0 & 1 & 1 & 0\end{array}\right)$ corresponds to two extreme situations identified in [20], [21] as expressing an "analogical dissimilarity", namely, to "D is not to $\mathrm{C}$ as B is to A". In fact, it is not just a simple negation here stating that the analogical proportion fails to hold, but rather the respective situations of $\mathrm{A} \mathrm{w}$. r. t. B, and of $\mathrm{C}$ w.r.t. D are here antonymic.

Remark 2. There exists, in the "set element-interpretation", another characterization of the analogical proportion due to [24], [25]. Letting A, B, C, D be subsets of X, (A : B :: C : D) holds if and only if there exist subsets $U, V, W, Z$, such as $\mathrm{A}=\mathrm{U} \cup \mathrm{V}, \mathrm{B}=\mathrm{U} \cup \mathrm{W}, \mathrm{C}=\mathrm{Z} \cup \mathrm{V}, \mathrm{D}=\mathrm{Z} \cup \mathrm{W}$. This decomposition is not unique, and the sets $\mathrm{U}, \mathrm{V}, \mathrm{W}, \mathrm{Z}$ do not need to be disjoint. When they are, this provides a constructive description of the analogical process: X (resp. Z) is the elements that are untouched when going from A and B (resp. from $\mathrm{C}$ and D), while the elements in $\mathrm{V}$ go out, and while those in $\mathrm{W}$ go in. It could be checked that this view exactly parallels the logical expression (6) of the analogical proportion.

\section{Analogical dissimilarity}

To go further, it is interesting to have a measure of how much the Boolean items a, b, c and d are close to be in analogical proportion. We call this measure analogical dissimilarity, denoted $\operatorname{AD}(\mathrm{a}, \mathrm{b}, \mathrm{c}, \mathrm{d})[20]$. Whenever $(\mathrm{a}: \mathrm{b}:: \mathrm{c}$ $: \mathrm{d})=1, \mathrm{AD}(\mathrm{a}, \mathrm{b}, \mathrm{c}, \mathrm{d})=0$. In the two special cases $(1,0,0$, 1) and $(0,1,1,0), \mathrm{AD}$ takes the value 2 . In all the other cases, we have $\mathrm{AD}=1 . \operatorname{AD}(\mathrm{a}, \mathrm{b}, \mathrm{c}, \mathrm{d})$ has a simple interpretation : it is the number of the binary values among a, $\mathrm{b}, \mathrm{c}$, and $\mathrm{d}$ that have to be flipped to turn $\mathrm{AD}$ into 0 . For example, $\mathrm{AD}(1,0,1,0)=0, \mathrm{AD}(1,0,1,1)=1, \mathrm{AD}(1,0,0$, $1)=2$. From a numerical point of view, $\operatorname{AD}(\mathrm{a}, \mathrm{b}, \mathrm{c}, \mathrm{d})=$ $|(a-b)-(c-d)|$. This expression readily extends to the additive analogical dissimilarity in the graded case, where a, $\mathrm{b}, \mathrm{c}$ and $\mathrm{d}$ are no longer restricted to binary values.

As explained in [2], AD has interesting properties that are quite useful in machine learning applications. The following inequality is particularly interesting in lazy learning methodologies:

$$
\mathrm{AD}(\mathrm{a}, \mathrm{b}, \mathrm{c}, \mathrm{d}) \leq \mathrm{AD}(\mathrm{a}, \mathrm{b}, \mathrm{e}, \mathrm{f})+\mathrm{AD}(\mathrm{e}, \mathrm{f}, \mathrm{c}, \mathrm{d}) .
$$

This inequality holds true not only in the binary case, but also in other extensions of the basic definition of the analogical proportion. A numerical analogical similarity AS can also be defined between 0 and 1 :

$$
\operatorname{AS}(a, b, c, d)=1-1 / 2|(a-b)-(c-d)| .
$$

\section{GRADED CASE}

When going from the binary case to the grades (or fuzzy) case where truth values now belong to $[0,1]$, many choices are possible for defining the connectives, and it should be clear that some of the equivalences previously found may now fail to hold since whatever the choices, we shall be no longer in a Boolean algebra. Because of the lack of space, we shall only consider in the following some of the choices that seem to be especially worth considering. The systematic study of what equivalences remain true in general setting such as MV algebras, or the practical use of parameterized families of triangular norms or related operations is left for further research.

Let us recall that there are three main choices for the conjunction, namely $a \wedge b=\min (a, b), a \wedge b=a b$, or $a \wedge b=$ $\max (0, a+b-1)$, associated with the three disjunctions $a \vee b$ $=\max (a, b), a \vee b=a+b-a b$, or $a \vee b=\min (1, a+b)$ respectively.

Then there are two main ways for defining implications, either as $\mathrm{a} \rightarrow \mathrm{b}=\neg \mathrm{a} \vee \mathrm{b}$, or by residuation $\mathrm{a} \rightarrow \mathrm{b}=\sup \{\mathrm{x}$ | $\mathrm{a} \wedge \mathrm{x} \leq \mathrm{b}\}$. It leads to distinct implications for the first two pair of conjunction / disjunction, namely $\mathrm{a} \rightarrow \mathrm{b}=$ $\max (1-\mathrm{a}, \mathrm{b})$ (Dienes implication), and $\mathrm{a} \rightarrow \mathrm{b}=1$ if $\mathrm{a} \leq \mathrm{b}$, and $\mathrm{a} \rightarrow \mathrm{b}=\mathrm{b}$ if $\mathrm{a}>\mathrm{b}$ (Gödel implication) for $\mathrm{min} / \mathrm{max}$, $\mathrm{a} \rightarrow \mathrm{b}=1-\mathrm{a}+\mathrm{ab}$ (Reinchenbach implication) and $\mathrm{a} \rightarrow \mathrm{b}=$ $\min (1, \mathrm{~b} / \mathrm{a})$ if $\mathrm{a}>0$, and $\mathrm{a} \rightarrow \mathrm{b}=1$ if $\mathrm{a}=0$ (Goguen implication). For the last pair of conjunction / disjunction, one implication is obtained $\mathrm{a} \rightarrow \mathrm{b}=\min (1,1-\mathrm{a}+\mathrm{b})$ (Lukasiewicz implication).

The equivalence connective associated to Dienes implication is $\mathrm{a} \equiv \mathrm{b}=\min (\max (1-\mathrm{a}, \mathrm{b}), \max (1-\mathrm{b}, \mathrm{a}))=$ $\max (\min (a, b), \min (1-a, 1-b))$, to Gödel implication is $\mathrm{a} \equiv \mathrm{b}=1$ if $\mathrm{a}=\mathrm{b}$, and $\mathrm{a} \equiv \mathrm{b}=\min (\mathrm{a}, \mathrm{b})$ otherwise (in a crisp version, one may take $a \equiv b=0$ if $a \neq b$ ). Using min 
conjunction and Lukasiewicz implication, one gets $\mathrm{a} \equiv \mathrm{b}=$ $\min (\min (1,1-a+b), \min (1,1-b+a))=1-|a-b|$. Using min or product conjunction and Goguen implication, one gets $\mathrm{a} \equiv \mathrm{b}=\min (1, \mathrm{~b} / \mathrm{a}, \mathrm{a} / \mathrm{b})=\min (\mathrm{b} / \mathrm{a}, \mathrm{a} / \mathrm{b})=$ $\min (1, b / a) \cdot \min (1, a / b)$ for $a \neq 0, b \neq 0$ (if $a=0$ or $b=0$ the result is obtained by taking the limit). Then the symmetric difference is usually obtained as a $\Delta \mathrm{b}=1-(\mathrm{a} \equiv \mathrm{b})$.

Remarks 3 An equation such as $(\mathrm{a} \equiv \mathrm{b}) \equiv(\mathrm{c} \equiv \mathrm{x})=1$ may now have in some cases several solutions. Besides, note that in the above equation, we may not use the same equivalence connective for the central equivalence and the two others! One may also be interested in relaxed equations such as $(a \equiv b) \equiv$ $(\mathrm{c} \equiv \mathrm{x}) \geq \alpha$. Lastly, note that $\mathrm{a} \Delta \mathrm{b}=|\mathrm{a}-\mathrm{b}|$ is also a distance!

In the following, we only briefly discuss the fuzzification of the two symmetric definitions we have found, i.e.

$(\mathrm{a}: \mathrm{b}:: \mathrm{c}: \mathrm{d})=((\mathrm{a} \equiv \mathrm{b}) \wedge(\mathrm{c} \equiv \mathrm{d})) \vee((\mathrm{a} \equiv \mathrm{c}) \wedge(\mathrm{b} \equiv \mathrm{d}))$
$(\mathrm{a}: \mathrm{b}:: \mathrm{c}: \mathrm{d})=((\mathrm{a} \rightarrow \mathrm{b}) \equiv(\mathrm{c} \rightarrow \mathrm{d})) \wedge((\mathrm{b} \rightarrow \mathrm{a}) \equiv(\mathrm{d} \rightarrow \mathrm{c}))(B)$

using one of the three choices:

- i) $a \wedge b=\min (a, b) ; a \vee b=\max (a, b) ; a \rightarrow b=$ $\max (1-a, b) ; a \equiv b=\min (a \rightarrow b, b \rightarrow a)$

- ii) $\mathrm{a} \wedge \mathrm{b}=\min (\mathrm{a}, \mathrm{b}) ; \mathrm{a} \vee \mathrm{b}=\max (\mathrm{a}, \mathrm{b}) ; \mathrm{a} \rightarrow \mathrm{b}=$ $\max (1, b / a) ; a \equiv b=\min (b / a, a / b)$;

- iii) $\mathrm{a} \wedge \mathrm{b}=\min (\mathrm{a}, \mathrm{b}) ; \mathrm{a} \vee \mathrm{b}=\max (\mathrm{a}, \mathrm{b}) ; \mathrm{a} \rightarrow \mathrm{b}=$ $\min (1,1-a+b) ; a \equiv b=1-|a-b|$.

These choices have been partly dictated by the fact that choices iii) and ii) seem respectively consonant with the view of analogical proportion as the equality of the differences (a $\mathrm{b}=\mathrm{c}-\mathrm{d})$, or of the ratios $(\mathrm{b} / \mathrm{a}=\mathrm{d} / \mathrm{c})$. Besides, $(A)$ and $(B)$ should coincide under interpretation $\mathrm{i})$.

For example, using $(B)$ and (iii), taking $\mathrm{s}$ and $\mathrm{t}$ as small positive numbers, we get: $(\mathrm{a}: \mathrm{a}:: \mathrm{c}: \mathrm{c}+\mathrm{s})=1-\mathrm{s}$, as well as $(\mathrm{a}: \mathrm{a}+\mathrm{s}:: \mathrm{c}: \mathrm{c}-\mathrm{t})=1-\min (\mathrm{s}, \mathrm{t})$. In the numerical additive context, using the expression: $|(a-b)-(c-d)|$ (see section II C), we would have obtained $(1-s)$ and $1-(s+t)$. The choice of this fuzzification and of this definition of the logical analogical proportion lead to a definition of the graded logical analogical proportion very similar to the classical numerical additive definition of the analogical proportion. In other words, we have defined through a logical setting an analogical dissimilarity very similar to that of the numerical case.

Mind, however, that the fuzzy counterpart of Proposition 5 (or 6) cannot be straightforwardly applied for finding the solution of an analogical proportion in the graded case. Proper equivalent expressions have to be found. For instance, if we use $((b \rightarrow a) \rightarrow c)$ if $a \rightarrow b=1$, and $\neg(c \rightarrow \neg(a \rightarrow b))$ if $\mathrm{b} \rightarrow \mathrm{a}=1$, which is indeed equivalent to $(\mathrm{a} \equiv(\mathrm{b} \equiv \mathrm{c}))$ in the binary case, we shall obtain with Lukasiewicz implication, $\min (1, c+(b-a))$ if $a \leq b$, and $\max (0, c-(a-b))$ if $a \geq b$, which are normalized versions of the solution of the numerical equation $\mathrm{a}-\mathrm{b}=\mathrm{c}-\mathrm{d}$. The systematic investigation of proper graded extensions is left for further research.

\section{APPLICATIONS}

As announced in the introduction, there are several potential applications of the approach proposed here to approximate and case-based reasoning, and to machine learning. We only outline them here.

For approximate reasoning, we have to use the "set element-interpretation" reading. Given a subset $\mathrm{A}^{\prime} \subseteq \mathrm{X}$, and some pair (A, B) associated with a fuzzy rule, one may compute a subset $\mathrm{B}^{\prime}$ such as $\left(\mathrm{A}: \mathrm{A}^{\prime}:: \mathrm{B}: \mathrm{B}^{\prime}\right)=1$ in the sense of extensions of definitions (8) or (9), once the fuzzy connectives have been chosen. One may also directly apply extensions of Propositions 5 or 6 (taking also into account some fuzzy counterpart of Proposition 4). Depending on the different choices, these constructions may be equivalent or not. It will generally departs from usual forms of Zadeh's generalized modus ponens [28], [9], and may come closer to patterns discussed in [4], [5], [6], [7], which starts from the possible definitions of the similarity between two fuzzy sets.

But the above approach requires that $\mathrm{A}$ and $\mathrm{B}$ be defined on the same referential, which is a severe limitation. If it is not the case, one may define a one-to-one correspondence between the referential X of A and the referential Y of B. In order to be meaningful, this correspondence $\tau$ should be such as $\left(\operatorname{small}_{\mathrm{X}}(\mathrm{x}): \operatorname{small}_{\mathrm{Y}}(\tau(\mathrm{x})):: \operatorname{large}_{\mathrm{X}}(\mathrm{x}): \operatorname{large} \mathrm{Y}_{\mathrm{Y}}(\tau(\mathrm{x}))\right)=1$ for all $\mathrm{x}$ in $\mathrm{X}$, where small $_{\mathrm{X}}$ and large $_{\mathrm{X}}\left(\right.$ resp. small $\mathrm{Y}_{\mathrm{Y}}$ and large $\left.\mathrm{C}_{\mathrm{Y}}\right)$ are fuzzy sets of $\mathrm{X}$ (resp. Y). This condition expresses a kind of commensurateness of two numerical domains by making sure that what is termed 'small', or 'large', in a domain corresponds to a value qualified in a similar way in the other domain. Then B' will be a solution of

$$
\left(\mathrm{A}(\mathrm{x}): \mathrm{A}^{\prime}(\mathrm{x}):: \mathrm{B}(\tau(\mathrm{x})): \mathrm{X}(\tau(\mathrm{x}))\right)=1 \text { for all } \mathrm{x} \text { in } \mathrm{X}
$$

However, there is another way that one may think of for using analogical reasoning in relation to approximate reasoning. Assume we have three rules "If $x$ is $A_{1}$ then $y$ is $B_{1}$ ", "If $x$ is $A_{2}$ then $y$ is $B_{2}$ ", and "If $x$ is $A_{3}$ then $y$ is $B_{3}$ ", and a fact " $\mathrm{x}$ is $\mathrm{A}$ " ", and we look for the associated " $\mathrm{y}$ is $\mathrm{B}$ "”. Let us further assume that the following analogical proportion holds $\left(A_{1}: A_{2}:: A_{3}: A^{\prime}\right)=1$ (or is very close to 1 ). Then, one may think of computing $B^{\prime}$, as being the solution of a similar analogical proportion, namely $\left(\mathrm{B}_{1}: \mathrm{B}_{2}:: \mathrm{B}_{3}: \mathrm{X}\right)=1$ Thus, we will also have $\left(\left(\mathrm{A}_{1}, \mathrm{~B}_{1}\right):\left(\left(\mathrm{A}_{2}, \mathrm{~B}_{2}\right)::\left(\left(\mathrm{A}_{3}, \mathrm{~B}_{3}\right):\left(\left(\mathrm{A}^{\prime}, \mathrm{X}\right)\right)\right.\right.\right.$.

Regarding case-based reasoning, the "object propertiesinterpretation" seems more suitable. Let us, for instance, consider the case of houses to let for vacations described in terms of three attributes (size, distance to the sea, price). Let us introduce three increasing membership functions on each attribute domain. They correspond to the idea of 'large', 'far', and 'expensive'. Given a repertory of houses, and a new house whose price is unknown, one may be led to the following analogical proportion equations such as

$\left(\left(\operatorname{large}\left(\mathrm{h}_{\mathrm{i}}\right), \operatorname{far}\left(\mathrm{h}_{\mathrm{i}}\right)\right): \operatorname{expensive}\left(\mathrm{h}_{\mathrm{i}}\right)::((\operatorname{large}(\mathrm{h}), \operatorname{far}(\mathrm{h})): \mathrm{x})=1\right.$ 
where $h_{i}$ is a house in the repertory, $h$ is the house whose price is unknown, and the first term of the analogy is computed as e.g., $a=\min \left(\right.$ large $\left.\left(h_{i}\right), f a r\left(h_{i}\right)\right)$ and the third term similarly. Then one can find solution(s) $\mathrm{x}=$ expensive(h) for the equation. Mind that if we use bell-shaped membership functions, the membership grade $\mathrm{x}$ may correspond to two prices ... The comparison of this approach with methods developed in [8], [10], [13], is an open question.

We may also think of using the analogical proportion in another way, using three complete cases (described as having a n-tuple of properties each of them to some extent) and another case to be completed. For instance, knowing how varies the price of a house according as it has or not some special equipment (from the cases of two houses quite similar, one having the equipment and the other not), and the knowledge of a quite different, third house having the equipment, try to guess the price of a fourth house quite similar to the third one, except it does not possess the equipment ...

As far as machine learning is concerned, the approach could be applied to finite sets, to t-uples of attribute values, but also to sequences and other structures sets. The concept of analogical dissimilarity has already been proven useful in classification problems [2] on binary and nominal data. It has already been extended to dissimilarity between 4-uples of strings, with applications to linguistic data as well as on-line handwritten characters [25], [3]. Analogical dissimilarity between tree structures, with application to written and spoken language is currently studied for machine learning applications.

\section{CONCLUDING REMARKS}

The paper has proposed a logical formalization of the idea of analogical proportion first for two-valued truth-values. As far as we know, this approach is original, since such a logical modeling was not laid bare before. It enables us to extend the approach to graded truth-values in a natural way. Clearly much remain to do, in particular i) to fully investigate the meaningful extensions with fuzzy connectives, ii) to compare them with numerical approaches, and iii) to fully discuss the applications outlined in the previous section.

\section{REFERENCES}

[1] A. Aamodt, E. Plaza, "Case-based reasoning: Foundational issues, methodological variations, and system approaches," Artificial Intelligence Communications 7 (1), pp. 39-52, 1994.

[2] S. Bayoudh, L. Miclet, A. Delhay, Learning by analogy: A classification rule for binary and nominal data" Proc. Inter. Joint Conf. on Artificial Intelligence, 678-683, 2007

[3] S. Bayoudh, H. Mouchère, L. Miclet, E. Anquetil, Learning a classifier with very few examples: Analogy-based and knowledge based generation of new examples for character recognition. Proc. Europ Conf. on Machine Learning, Springer Verlag, LNAI 4701, 2007.

[4] B. Bouchon-Meunier, "Fuzzy analogy," Proc. 12th Inter. Conf. on Intelligent and Adaptive Systems and Software Engineering (IASSE 2003), (A. Satyadas, S. M. Dascalu, eds.), July 9-11, 2003, San Francisco, Ca, pp. 97-100.

[5] B. Bouchon-Meunier, L. Valverde, "A fuzzy approach to analogical reasoning,"Soft Computing 3, pp. 141-147, 1999.

[6] B. Bouchon-Meunier, L. Valverde "A resemblance approach to analogical reasoning functions," In Fuzzy Logic in Artificial Intelligence:
Towards Intelligent Systems (T. P. Martin, A.L. Ralescu, eds.), IJCAI'95 Workshop, Monréal, Canada, August 19-21, 1995, Selected Papers. LNCS 1188, Springer 1997, pp. 266-272.

[7] B. Bouchon-Meunier, M. Rifqi, "A framework to unify and generate measures of comparison," Tatra Mountains Mathematical Publications, pp. 89-97, 1997.

[8] D. Dubois, F. Esteva, P. Garcia, L. Godo, R. Lopez de Mantaras, H. Prade "Fuzzy modelling of cased-based reasoning and decision," Proc. 2nd Inter. Conf. on Cased-Based Reasoning (ICCBR-97), Providence, July 25-27, 1997, Springer-Verlag, Berlin, LNCS 1266, pp. 599-610.

[9] D. Dubois, F. Esteva, L. Godo, H.Prade. Fuzzy-set based logics - An History-oriented presentation of their main developments, In Handbook of the History of Logic, Vol. 8: The Many Valued and Non-monotonic Turn in Logic, (D. M. Gabbay and J. Woods, eds.), pp. 325-449. Elsevier, 2007.

[10] D. Dubois, E. Hüllermeier, H. Prade. "Fuzzy set-based methods in instance-based reasoning, " IEEE Transactions on Fuzzy Systems, 10, pp. 322-332, 2002.

[11]T. G. Evans, "A heuristic program to solve geometry analogy problems," in Semantic Information Processing, (M. Minsky, ed.), MIT Press, Cambridge, 1968.

[12] H. Farreny, H. Prade, "About flexible matching and its use in analogical reasoning," Proc. of the 1982 European Conf. on Artificial Intelligence (ECAI-82), Orsay, France, July 12-14, pp. 43-47.

[13] E. Hüllermeier, "Case-based approximate reasoning," Theory and Decision Library B 44, Dordrecht, Springer, 2007.

[14] S. Klein, "Culture, mysticism \& social structure and the calculation of behavior," Proc. of the 1982 European Conf. on Artificial Intelligence (ECAI-82), Orsay, France, July 12-14, pp. 141-146.

[15] S. Klein, "The analogical foundations of creativity in language, culture \& the arts: the upper paleolithic to 2100CE." In Language, Vision \& Music, (P. McKevitt,_C. Mulvihill \& S. O' Nuallin, eds.), John Benjamin, Amsterdam, pp. 347-371, 2002.

[16] R. E. Kling, "A paradigm for reasoning by analogy," Artificial Intelligence, 2, pp. 147-178, 1971.

[17] Léa Sombé, "Reasoning by analogy," chap. XII in Reasoning Under Incomplete Information in Artificial Intelligence, Special issue Int. J. Intelligent Systems, 5 (4), Wiley, 1990, pp. 418-424.

[18] Y. Lepage, "De l'analogie rendant compte de la commutation en linguistique," Habilitation à Diriger les Recherches, Université Joseph Fourier, Grenoble, 2003.

[19] L. Miclet, A. Delhay, "Relation d'analogie et distance sur un alphabet défini par des traits," INRIA Research Report n5244, July 2004.

[20] L. Miclet, A. Delhay, "Analogical dissimilarity: definition, algorithms and first experiments in machine learning," INRIA Research Report $\mathrm{n}^{\circ} 5694$, September 2005.

[21] L. Miclet, S. Bayoudh, A. Delhay, H. Mouchère, "De l'utilisation de la proportion analogique en apprentissage artificiel," Journées Intelligence Artificielle Fondamentale, Plateforme AFIA, Grenoble July 2-3, 2007, http://gdri3iaf.info.univ-angers.fr/IMG/pdf/MicletVersionFinale.pdf.

[22] H. Prade, "Analogie, flou et systèmes experts," BUSEFAL n³2, 1987, pp.108-114. http://www.listic.univ-savoie.fr/modules.php?name=Busefal

[23] S. D. Siemens, "On Klein's "Analogy and mysticism and the structure of culture"' Current Anthropology, 29, pp. 471-483, 1988.

[24] N. Stroppa, F. Yvon. "Analogies dans les séquences : un solveur à états finis," In Actes de la $11^{\text {ieme }}$ Conférence Annuelle sur le Traitement Automatique des Langues Naturelles (TALN 2004), Fès, Maroc, April 2004

[25] N. Stroppa, F. Yvon. "Du quatrième de proportion comme principe inductif : une proposition et son application à l'apprentissage de la morphologie," Traitement Automatique des Langues, 47(2), pp. 33-59, 2006.

[26] N. Stroppa, F. Yvon. Formal models of analogical proportions. ENST Tech. Rep. 2007. http://www.tsi.enst.fr/publications/enst/techreport2007-6830.pdf

[27] P. H. Winston, "Learning and reasoning by analogy," Communications of the ACM, 23, pp. 689-703, 1980.

[28] L. A Zadeh, "A theory of approximare reasoning," In Machine Intelligence 9, (J. E. Hayes, D. Mitchie, L. I. Mikulich, eds.), Wiley, New York, pp. 149-194. 